\title{
ANALISIS CUALITATIVO Y CUANTITATIVO DE LA RESPUESTA INMUNE HUMORAL A Plasmodium falciparum EN PERSONAS PROTEGIDAS Y NO PROTEGIDAS
}

\author{
MARTHA LUCIA MORENO S.* , LUIS LEONARDO URREA A.**, MOISES WASSERMAN L.*
}

En este trabajo se buscaron diferencias en los patrones de reconocimiento de proteínas de Plasmodium falciparum por anticuerpos de pacientes con distintos grados de inmunidad protectiva. Evaluamos 50 sueros provenientes de un área hiperendémica, de personas que mostraron un grado de protección, 50 sueros de personas no protegidas que sufrían infecciones activas y 30 sueros de personas que nunca tuvieron malaria. Los anticuerpos se estudiaron por los métodos de inmunoprecipitación y de inmunotransferencia, y se buscó presencia o ausencia de cada banda en alguno de los grupos.

Se encontró un nivel de anticuerpos más alto y un patrón de reconocimiento más complejo en los sueros de personas no protegidas. Sólo un anticuerpo, que reconoce una proteína de $99 \mathrm{kDa}$, y que fue encontrado en el $40 \%$ de las personas protegidas parece tener alguna relación (aunque débil) cori protección. Nuestros resultados sugieren que la respuesta inmune humoral es más un indicativo de una infección reciente que de un estado de protección.

\section{INTRODUCCION}

Es importante para el conocimiento de la malaria, el estudio de la relación entre respuesta inmune mediada por anticuerpos y el grado de protección en un individuo. Experimentos de transferencia pasiva de $\mathrm{IgG}$ de sueros inmunes a individuos infectados que produjeron una fuerte disminución en sus parasitemias, es evidencia concluyente de que hay anticuerpos específicos que juegan un papel importante en la resistencia del hombre al desarrollo del Plasmodium falciparum (1).

REESE (2) propone la existencia de dos puntos en el ciclo asexual que son potencialmente atacables por el sistema inmune humoral: el primer punto es el eritrocito parasitado. Durante la maduración dentro del glóbulo rojo, el $P$. falciparum altera la membrana del eritrocito creando estructuras inmunogénicas a las cuales tanto humanos como monos responden con anticuerpos. El segundo punto por el cual el ciclo asexual eritrocítico puede ser interrumpido por la respuesta inmune es el estadío de merozoíto. Los anticuerpos se unen a la superficie del merozoíto e inhiben la reinvasión.

Para buscar diferencias claras en la respuesta a proteínas antigénicas específicas entre sueros de personas con diferente grado de inmunidad, se utilizaron en este trabajo las técnicas de inmunoprecipitación e inmunotransferencia.

* Grupo de Bioquímica, Instituto Nacional de Salud. Bogotá, COLOMBIA.

**Facultad de Ciencias, Universidad Nacional de Colombia. Bogotá, COLOMBIA. 


\section{MATERIALES Y METODOS}

\section{Cultivo del parásito}

Todo el trabajo experimental se realizó con la cepa colombiana FCB-2 (3). Los parásitos se cultivaron según el método de Trager y Jensen $(4,5)$ en una suspensión de eritrocitos humanos tipo 0 al $5 \% \mathrm{v} / \mathrm{v}$ en medio RPMI-1640 (SIGMA Co) suplementado con suero humano al $10 \%$, hipoxantina $0.02 \mathrm{mM}$, glutation reducido $1 \mathrm{mg} / 1$, HEPES $25 \mathrm{mM}$, bicarbonato de sodio $32 \mathrm{mM}$ y ğentamicina $50 \mathrm{mg} / \mathrm{l}$. El cultivo se mantuvo a $37^{\circ} \mathrm{C}$ en atmósfera de $\mathrm{CO}_{2} 5 \%, 0_{2} 5 \%$ y $\mathrm{N}_{2} 90 \%$.

\section{Sincronización de cultivo}

El cultivo del parásito que crece asincrónicamente se sincronizó con sorbitol al 5\% (6) cuando su parasitemia en anillos fue de $3 \%$ o más.

\section{Concentración de esquizontes}

Se realizó por el procedimiento descrito por Rivadeneira y $\mathrm{Col}$. (7) cuando el cultivo tuvo una parasitemia en esquizontes superior al 5\% utilizando Percoll (PHARMACIA) al $90 \%$ en buffer salino $\mathrm{pH} 7.4$ (HBS).

\section{Obtención de antígeno}

Los esquizontes obtenidos se trataron con un volumen igual de saponina al $0.1 \%$ en HBS. El antígeno crudo obtenido fue almacenado a $-20^{\circ} \mathrm{C}$ y periódicamente extraído antes de su uso con Triton X-100 al $2 \%$ en HBS.

\section{Marcación de cultivo}

Se preparó un medio libre de metionina, el cual después de ser evaluado en cultivo se utilizó suplementado con suero humano al $10 \%$, bicarbonato de sodio $32 \mathrm{mM}$, glutatión $1 \mathrm{mg} / \mathrm{l}$ y $35 \mathrm{~S}$-metionina $(25 \mu \mathrm{Ci} / \mathrm{ml}$, actividad específica $1300 \mathrm{Ci} / \mathrm{mmol}$ ) sobre cultivo sincronizado permitiéndose la marcación durante todo el ciclo del parásito. Los esquizontes fueron concentrados con Percoll al 90\%, lisados con saponina y extraídos con Triton X-100 al 2\% en HBS.

\section{Clasificación de sueros}

Los sueros fueron clasificados de acuerdo con su historia clínica, así: a) sueros de pacientes protegidos (P): De personas residentes en un área endémica (Tumaco e Industrias PROPAL) que tienen anticuerpos contra $P$. falciparum y que en el último año no han sufrido la enfermedad, y sueros de Aotus trivirgatus que fueron inmunizados en el laboratorio con merozoítos y posteriormente resistieron un reto.

b) Sueros de pacientes no protegidos (NP): En general de personas que han sido remitidas al INS con síntomas de la enfermedad y con presencia de parásitos en sangre periférica.

c. Sueros controles $(\mathrm{C})$ : de personas que no han estado nunca enfermas de malaria.

\section{Electroforesis}

Se realizaron en geles de poliacrilamida de $1.5 \mathrm{~mm}$ de espesor. El gel separador fue de $\mathrm{T}=7.5 \%$ y $\mathrm{C}=$ $2.7 \%$, en buffer Tris- $\mathrm{HCl} 0.37 \mathrm{M} \mathrm{pH} \mathrm{8.8,} \mathrm{SDS} 0.1 \%$; y el gel concentrador de $\mathrm{T}=4 \%$ y $\mathrm{C}=2.7 \%$ en buffer Tris- $\mathrm{HCl} 0.12 \mathrm{M}$ pH 6.8, SDS $0.1 \%$. Se empleó como buffer de corrida Tris $0.025 \mathrm{M} / 0.2 \mathrm{M}$ de glicina $\mathrm{y}$ SDS $0.1 \%$

Las muestras fueron tratadas previamente con buffer Tris- $\mathrm{HCl} 0.12 \mathrm{M} \mathrm{pH} \mathrm{6.8.4 \%} \mathrm{SDS,} 10 \% \beta$-mercaptoetanol y glicerol al $20 \%$ a $45^{\circ} \mathrm{C}$ durante 15 minutos y posteriormente a $92^{\circ} \mathrm{C}$ durante 5 minutos.

Las electroforesis se corrieron a $20 \mathrm{~mA}$ hasta que las muestras sobrepasaron el gel concentrador y a 60 $\mathrm{mA}$ durante 3 horas.

Con excepción de los geles que se transfirieron, la tinción se realizó sumergiendo el gel en una solución al $0.03 \%$ de azul de Comassie en ácido acético $10 \%$ e isopropanol $10 \%$ durante la noche, decolorando posteriormente en la misma solución sin colorante y secando por calor y vacío sobre papel whatman $3 \mathrm{~mm}$.

\section{Inmunotransferencia}

El antígeno no marcado fue separado por PAGESDS y transferido a membrana de nitrocelulosa durante 3 horas a $0.5 \mathrm{~A}$.

La membrana fue bloqueada para prevenir uniones no específicas de proteínas del suero con PBS-Tween $200.5 \%$ y albúmina bovina $2 \mathrm{mg} / \mathrm{ml}$ durante 1 hora 
a $37^{\circ} \mathrm{C}$ e incubada con los sueros de interés en dilución 1:200 en PBS-Tween $200.5 \%$ Triton X-100, SDS $0.02 \%$ y albúmina bovina $1 \mathrm{mg} / \mathrm{ml}$ con agitación a $4^{\circ} \mathrm{C}$ durante la noche. Las membranas se lavaron con PBS-Tween-Triton durante 15 minutos (3 veces) después de lo cual fueron incubadas con IgG de cabra anti-IgG humano conjugada con fosfatasa alcalina en dilución 1:2000 4 horas a $4^{\circ} \mathrm{C}$ (en PBS-Tween-Triton $\mathrm{X}-100$ ). El complejo fue revelado con Azul de nitrotetrazoliom (NBT) y 5-bromo, 4-cloro 3-indolilfosfato (BCIP).

\section{Inmunoprecipitación}

Una cantidad de antígeno marcado equivalente a $4 \times 10^{6} \mathrm{dpm}$ fue incubada con $10 \mu \mathrm{l}$ de suero en 0.4 $\mathrm{ml}$ de HBS durante 30 minutos a temperatura ambiente y toda la noche a $4^{\circ} \mathrm{C}$. Se agregaron $35 \mu \mathrm{l}$ de inmunoprecipitina $10 \%$ (BRL) y se incubó 30 minutos a $37^{\circ} \mathrm{C}$.
Se hicieron entonces 3 lavados con $10 \mathrm{ml}$ de buffer Tris- $\mathrm{HCl} \mathrm{pH} 8.3$ centrifugando a 500xg. El precipitado fue tratado posteriormente con $50 \mathrm{ul}$ de buffer muestra para PAGE-SDS.

Una vez corrida la electroforesis y fijadas las proteínas el gel fue incubado con ENHANCER (AMERSHAM) por dos horas a temperatura ambiente, se secó por calor y vacío y se dejó expuesto en fluorografía con película Hyperfilm- $\beta$ max durante 5 días.

\section{RESULTADOS}

Se llevaron a cabo inmunotransferencias (figura 1) e inmunoprecipitaciones (figura 2) para 30 sueros controles, 51 de pacientes que tienen anticuerpos contra la malaria pero no están protegidos y 47 de individuos que tienen evidencias de estar protegidos (ver clasificación de sueros en Materiales y Métodos).

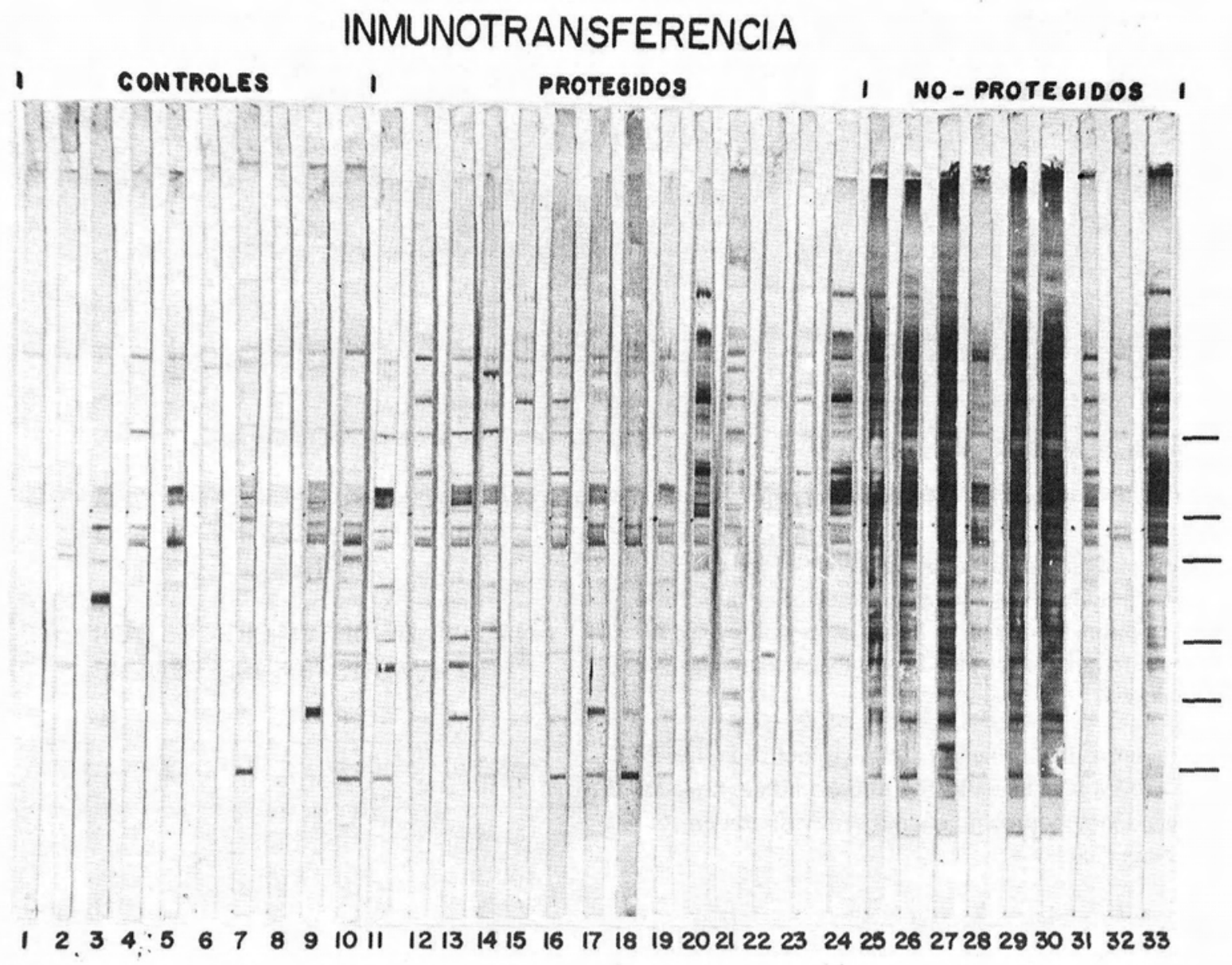

Figura 1. Inmunotransferencia de sueros representativos de los 3 grupos (controles, protegidos y no protegidos). 


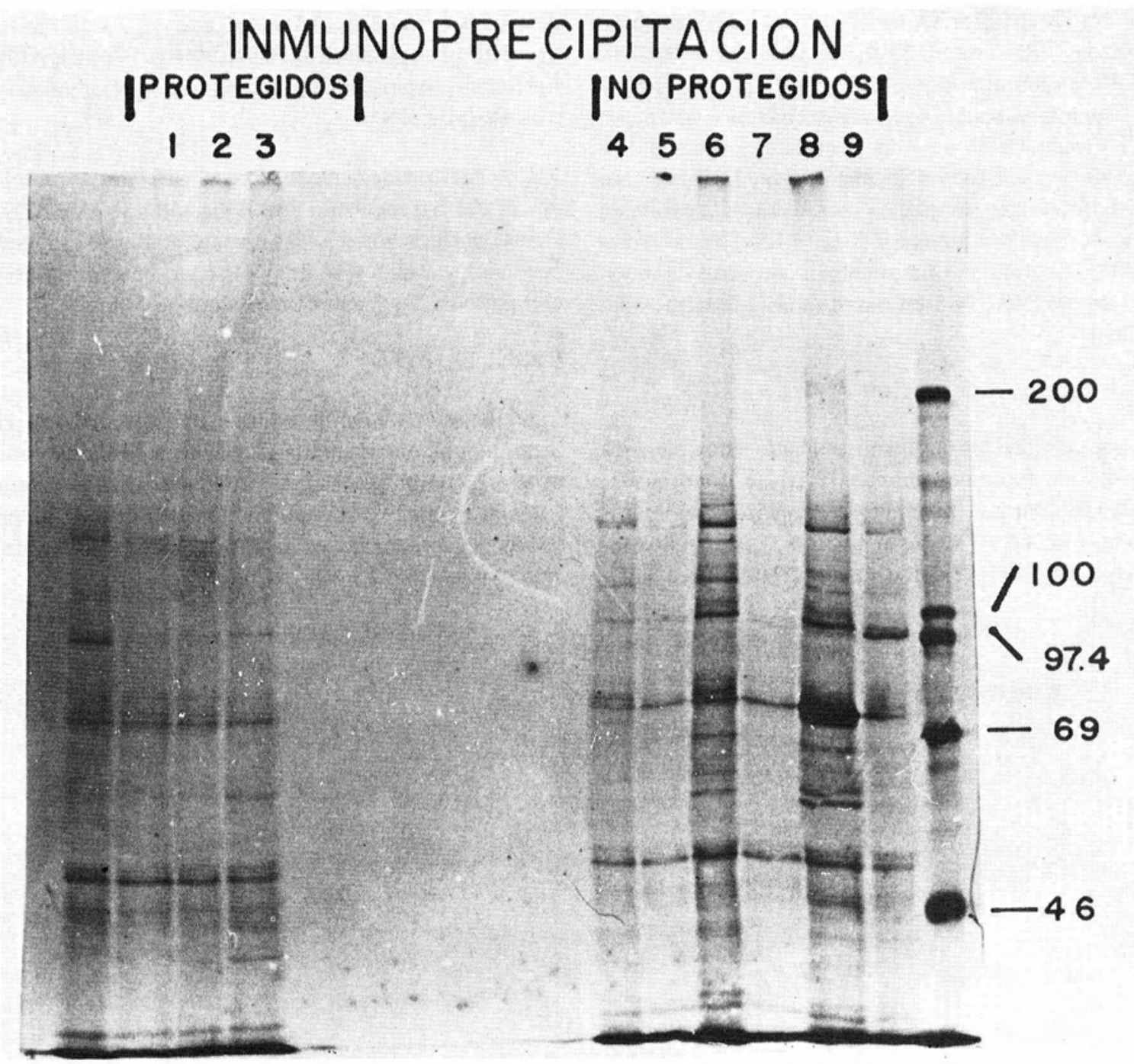

Figura 2. Inmunoprecipitación de sueros representativos de los 3 grupos (controles, protegidos y no protegidos).

Para cada uno de los experimentos se hizo una gráfica de movilidad vs. logaritmo del peso molecular de los patrones utilizados. Sobre estas gráficas se hicieron interpolaciones para las bandas reconocidas por cada suero.

Se analizó la desviación estándar para cada uno de los patrones y de acuerdo con esto las inmunotransferencias e inmunoprecipitaciones se dividieron en cuatro zonas (Tablas 1 y 2 ).

A cada banda se le asignó un valor relativo de acuerdo a su intensidad: 1 para baja intensidad, 2 para media intensidad y 3 alta intensidad.
TABLA 1

ANALISIS DE DESVIACION ESTANDAR EN INMUNOTRANSFERENCIA

\begin{tabular}{crc}
\hline Zona (Kd) & Desv. Est. (Kd) & Ventana (Kd) \\
\hline$>100$ & \pm 1.50 & 3.0 \\
$100-50$ & \pm 0.75 & 1.5 \\
$50-30$ & \pm 0.50 & 1.0 \\
$<30$ & \pm 1.50 & 3.0 \\
\hline
\end{tabular}


TABLA 2

\section{ANALISIS DE DESVIACION ESTANDAR EN INMUNOPRECIPITACION}

\begin{tabular}{ccc}
\hline Zona (Kd) & Desv. Est. (Kd) & Ventana (Kd) \\
\hline$>100$ & \pm 2.0 & 4.0 \\
$100-85$ & \pm 0.75 & 1.5 \\
$85-65$ & \pm 0.50 & 1.0 \\
$<65$ & \pm 0.75 & 1.5 \\
\hline
\end{tabular}

Con estos datos fue alimentado un microprocesador y con un programa de análisis de datos se obtuvo la frecuencia con la que aparece cada banda con una determinada intensidad en los tres grupos.
Para analizar si las diferencias en presencia o en intensidad de una determinada banda son debidas a la diferencia en estatus inmune o si se puede atribuír al azar se recurrió a la prueba estadística chi cuadrado.

Se consideraron cuatro hipótesis, de acuerdo con el diagrama de la figura 3:

1. Hay reacción cruzada si los tres grupos son estadísticamente iguales en cuanto a presencia con una certeza dada (90 ó 95\%).

2. Se trata de una respuesta irrelevante si habiendo diferencias en presencia o en intensidad entre los tres grupos, los grupos de individuos protegidos y no protegidos son estadísticamente iguales en cuanto a presencia e intensidad.

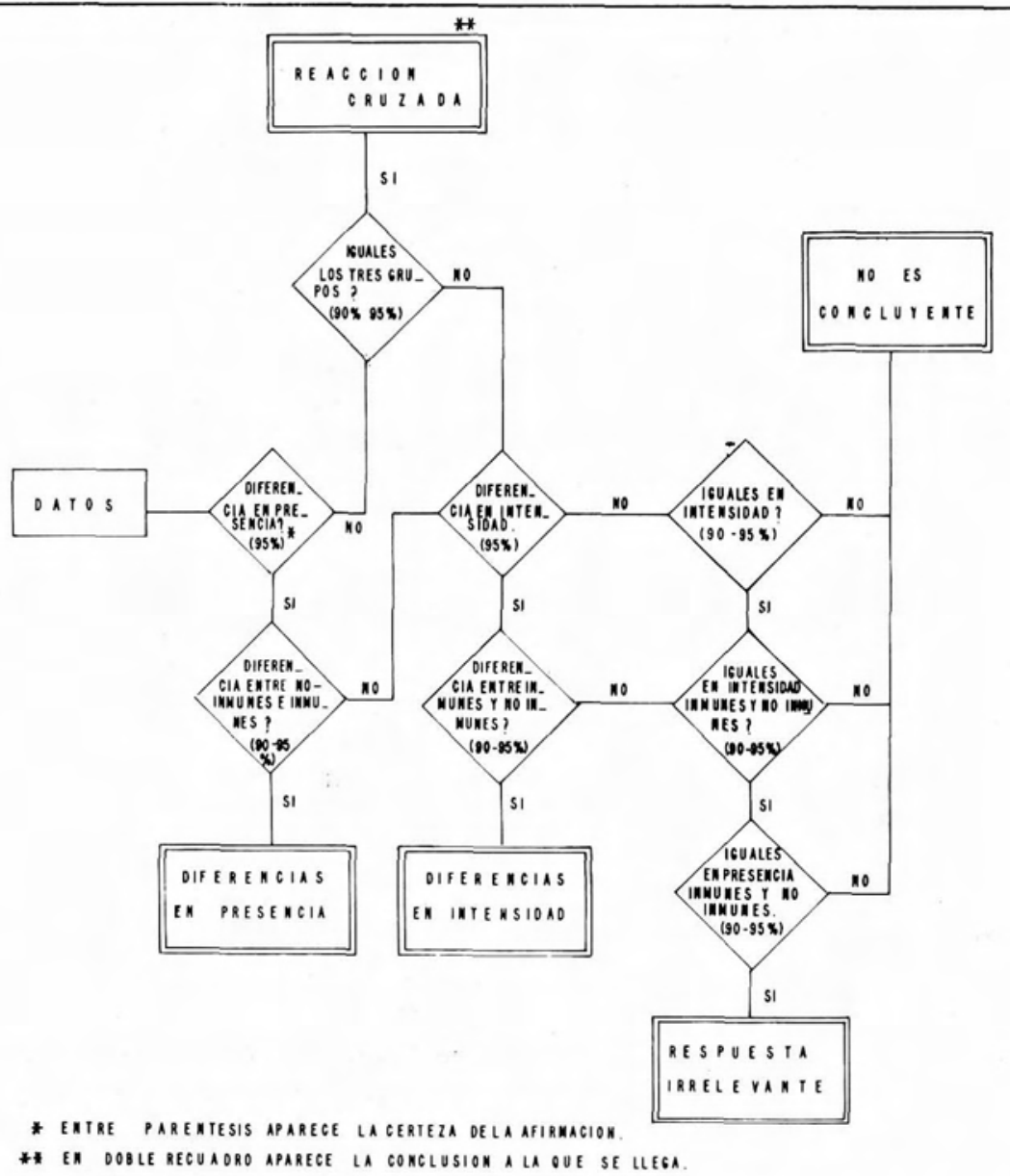

Figura 3. Diagrama de flujo utilizado en el análisis estadístico de frecuencias. 
3. Existen diferencias en presencia.

4. Existen diferencias en intensidad.

Este análisis fue aplicado a las bandas que aparecieron con una frecuencia mayor del $60 \%$ y del $40 \%$.

En inmunotransferencia aparecen con mayor frecuencia en el grupo de los no protegidos las bandas de $33,35,42,45,48,50,51,54,76.5$ y $165 \mathrm{Kd}$ y con mayor frecuencia con intensidad alta las de 27 , $70.5,73.5,111,114,117$ y $123 \mathrm{Kd}$. En el $60 \%$ o más de estos sueros se encuentran las de 27, 42, 45, 51, 54, 70.5 y $73.5 \mathrm{Kd}$. Existe tan sólo una banda, las de $99 \mathrm{Kd}$, con mayor frecuencia en el grupo de los protegidos (habitantes de un área endémica que no han presentado la enfermedad en el último año) que en el grupo de los no protegidos (Tabla 3). Estadísticamente puede afirmarse que esta diferencia es debida al estatus inmune, es decir, está realcionada con la inmunidad protectiva. Esta banda estuvo presente en el $42.5 \%$ de los sueros de este grupo.

TABLA 3

\section{ANALISIS ESTADISTICO PARA BANDAS CON FRECUENCIA MAYOR DEL $60 \%$ EN INMUNOTRANSFERENCIA}

\begin{tabular}{clc}
\hline Banda & \multicolumn{1}{c}{ Conclusión } & Certeza \\
\hline 27 & $\begin{array}{l}\text { Aparece con mayor intensidad } \\
\text { en el grupo de los no protegidos } \\
\text { Aparece con mayor frecuencia } \\
\text { en el grupo de los no protegidos } \\
\text { Aparece con mayor frecuencia } \\
\text { en el grupo de los no protegidos } \\
45\end{array}$ & $95 \%$ \\
51 & $\begin{array}{l}\text { Aparece con mayor frecuencia } \\
\text { en el grupo de los no protegidos } \\
\text { Aparece con mayor frecuencia } \\
\text { en el grupo de los no protegidos } \\
\text { No concluyente } \\
74.5\end{array}$ & $95 \%$ \\
73.5 & $\begin{array}{l}\text { Aparece con mayor intensidad } \\
\text { en el grupo de los no protegidos } \\
\text { Aparece con mayor intensidad } \\
\text { en el grupo de los no protegidos } \\
\text { No concluyente }\end{array}$ & $95 \%$ \\
90 & No concluyente & $95 \%$ \\
144 & & \\
\hline
\end{tabular}

TABLA 4

\section{ANALISIS ESTADISTICO PARA BANDAS CON FRECUENCIA MAYOR DEL $60 \%$ EN INMUNOPRECIPITACION}

\begin{tabular}{clc}
\hline Banda & \multicolumn{1}{c}{ Conclusión } & Certeza \\
\hline 31.5 & $\begin{array}{l}\text { Artefacto del sistema } \\
\text { Aparece con mayor intensidad } \\
\text { en el grupo de los no protegidos }\end{array}$ & $95 \%$ \\
48 & $\begin{array}{l}\text { Artefacto del sistema } \\
\text { Aparece con mayor frecuencia } \\
\text { en el grupo de los no protegidos } \\
58.5\end{array}$ & $\begin{array}{l}\text { Aparece con mayor frecuencia } \\
\text { en el grupo de los no protegidos }\end{array}$ \\
75 & $\begin{array}{l}\text { Artefacto del sistema } \\
\text { Aparece con mayor frecuencia } \\
\text { en el grupo de los no protegidos } \\
\text { Aparece con mayor frecuencia } \\
\text { en el grupo de los no protegidos }\end{array}$ & $95 \%$ \\
136 & $\begin{array}{l}\text { Aparece con mayor frecuencia } \\
\text { en el grupo de los no protegidos }\end{array}$ & $95 \%$ \\
\hline
\end{tabular}

Por la técnica de inmunoprecipitación se detectan con mayor frecuencia en el grupo de los no protegidos las bandas de $33,39,49.5,58.5,71,78,97.5,108$, 136 y $144 \mathrm{Kd}$, y con mayor frecuencia con intensidad alta la banda de $43.5 \mathrm{Kd}$. Las bandas $43.5,49.5$, $58.5,78,97.5$ y $136 \mathrm{Kd}$ estuvieron en el $60 \%$ o más (Tabla 4).

Mediante esta técnica no fue posible detectar anticuerpos relacionables con inmunidad protectiva.

\section{DISCUSION}

Los resultados del análisis de sueros por inmunotransferencia muestran en forma contundente una mayor respuesta de anticuerpos en aquellos individuos catalogados como no protegidos (habitantes de un área endémica que presentan la infección). Este resultado está de acuerdo con lo encontrado por autores como Abele et al, $(8,9)$ que muestran que las infecciones con $P$. falciparum causan un marcado incremento en la concentración de inmunoglobulinas del suero. Cohen et al, (1) encuentran que en individuos que habitan en un área holoendémica la velocidad con que se sintetiza IgG es siete veces mayor que en individuos sanos. 
La mayor frecuencia e intensidad de bandas en suero de individuos no protegidos se explicaría por las siguientes consideraciones: existe una activación de anticuerpos específicos contra proteínas internas y externas del parásito que sin embargo, no conlleva protección. Hay además una activación policlonal general, es decir, una alta producción de anticuerpos con una baja especificidad que induce un estado inmune de baja responsividad $(10,11,12)$. En inmunotransferencia, lo anterior se ve reforzado por el hecho de que los antígenos transferidos están expuestos directamente a todos los anticuerpos del suero, lo que facilita la detección de reacciones cruzadas y de otras de baja afinidad.

En inmunoprecipitación, aunque se observa el mismo comportamiento, la cantidad de bandas es menor posiblemente debido a que, por las características mismas de la técnica, sólo reacciones inmunológicas estables son reconocidas. Además, la marcación se hace con $35 \mathrm{~S}$-metionina poe la detección de cada una de las bandas depende de su contenido en este aminoácido.

Dentro del grupo de los protegidos se encuentran cuatro sueros de Aotus trivirgatus inmunizados en laboratorio. La inmunización se logra después de varios retos con el parásito en los cuales se llega a parasitemias relativamente altas (cerca del $30 \%$ ). Tales parasitemias inducen respuestas inmunes masivas de las cuales puede decirse que contienen anticuerpos relevantes en protección. Esto explica que su patrón de anticuerpos sea diferente al de sueros de individuos protegidos y no protegidos. Una observación interesante es que la banda de $99 \mathrm{Kd}$, que parece estar relacionada con protección, se encuentra en todos ellos.

En este tipo de análisis debe hacerse las siguientes consideraciones:

a) No hay información sobre la cepa o cepas de $P$. falciparum que causaron la infección en los individuos examinados. La variación en los organismos infectantes podría explicar parcialmente la variabilidad de la repuesta inmune. No obstante, es de anotar que muchos autores han coincidido en afirmar que la inmunidad protectiva trasciende tanto la variación fenotípica como la diversidad genotípica del parásito $(2,9)$. La experiencia misma nos muestra que, a pesar de que en un área holoendémica existan distintas cepas, los individuos inmunes lo son a todas ellas.

Hasta el momento la naturaleza de esta inmunidad trascendente no ha sido explicada. En cualquier caso, existen componentes inmunológicos importantes que hacen parte de todas las cepas y son capaces de inducir protección (2).

b) No es posible saber en qué punto del desarrollo de la infección fueron tomadas las muestras ni especular sobre el fin de ésta si los pacientes no hubiesen sido tratados. Esto constituye una incerticumbre al hacer comparaciones entre los patrones de anticuerpos de diferentes sueros.

c) La reacción de un antígeno con un anticuerpo no garantiza que el anticuerpo sea funcional (ya que la interacción puede ser con un determinante irrelevante), ni que el anticuerpo esté dirigido contra dicho antígeno porque pueden ocurrir fenómenos de coprecipitación y de reacción cruzada.

d) Por las características mismas de las técnicas sólo las inmunoglobulinas de tipo $\mathrm{G}$ son detectadas y, a pesar de que éstas tienen la propiedad de inhibir el crecimiento in vitro del parásito y que son las más importantes en la respuesta inmune, otras inmunoglobulinas podrían jugar algún papel en la protección hasta ahora no definido.

De cualquier manera, a partir de estos resultados se puede afirmar que en serología el nivel de anticuerpos indica, más que el grado de protección del individuo, que tan reciente ha sido la infección. Se puede afirmar también que hay una diferencia clara entre inmunidad humoral y protección. Así, en los individuos considerados como no protegidos hay una alta respuesta de este tipo pero ésta obviamente es irrelevante para la protección.

Druilhe \& Khusmith (13), Celada et al. (33), Brown et al. (9) y Perrin \& Dayal (10), entre otros, han mostrado la importancia de la inmunidad mediada por células en la protección y relación con anticuerpos específicos que reconocerían a los eritrocitos infectados y a los merozoítos que serán luego fagocitados por monocitos y macrófagos. Estos anticuerpos podrían estar enmascarados por respuestas más intensas de los anticuerpos señalados acá. 


\section{CONCLUSIONES}

Durante la infección con $P$. falciparum, hay una activación policlonal general de baja responsividad que se manifiesta en una mayor respuesta de anticuerpos en individuos no protegidos.

En inmunotransferencia se revela una banda de 99 $\mathrm{Kd}$ que podría relacionarse con inmunidad protectiva. Esta banda se observa también en el suero de los cuatro Aotus trivirgatus inmunizados.

Por inmunoprecipitación no fue posible detectar anticuerpos relacionables con inmunidad protectiva.

Los resultados están subordinados a factores como selectividad de los sistemas de inmunosorción y revelado, variaciones antigénicas debidas a cultivo in vitro por largo tiempo o a la variabilidad fenotípica y genotípica propia del parásito, y fenómenos concomitantes como reacciones cruzadas, uniones inespecíficas, etc.

El nivel de anticuerpos indica, más que el grado de protección del individuo, qué tan reciente ha sido la infección.

En estos experimentos no se observa una relación directa entre inmunidad humoral y protección.

La protección podría estar relacionada más directamente con la inmunidad celular.

\section{SUMMARY}

We searched for differences in the pattern of recognition of Plasmodium falcipararum proteins in sera from patients with diverse immunity degrees. We evaluated both by immunoprecipitation and by immnoblotting 50 sera from an endemic area, obtained from persons showing some degree of protection; 50 sera from infected individuals and 30 sera from persons who were never exposed to malaria.

A higher level of antibodies and a more complex pattern of recognitions was found with sera from unprotected patients.

Only one antibody, which recognized a $99 \mathrm{kDa}$ protein and which was present in $40 \%$ of the protected persons was related with protection (although only mildly). Our results suggest that the humoral immune response against malaria is an indicative of a recent infection rather than of a protective immune state.

\section{AGRADECIMIENTOS}

Este trabajo fue financiado por JICA (Japan International Cooperation Agency) y por el Fondo Colombiano de Investigaciones Científicas "Francisco José de Caldas" COLCIENCIAS. Los autores agradecen al doctor Sócrates Herrera de la Universidad del Valle por el suministro de sueros provenientes de un área endémica (Tumaco e Industrias Propal).

\section{BIBLIOGRAFIA}

1. Cohen S, Mcgregor I, Carrington S. Gammaglubulin and acquired immunity to human malaria. Nature 1961 192: 733-737.

2. Reese R. et al. Reaction of immune sera with components of the human malarial parasite, $P$. falciparum Am J Trop Med Hyg. 1981; 30 (6): 1168-1178.

3. Espinal C, Moreno E, Guerra P, De la Vega P. Aislamiento y caracterización de cepas colombianas de Plasmodium falciparum Biomédica, 2, 1982; 118-128.

4. Trager W, Jensen JB. Cultivation of malarial parasites. Nature, 1978; 273, 621-622.

5. Trager W, Jensen JB. Cultivation of malarial parasites in continous culture. Science. 1976; 193, 673-675.

6. Lambros \& Vanderberg. Syncronization of Plasmodium falciparum erythrocytic stages in culture. J Parasitol, 1979 ; 65, 418-420.

7. Rivadeneira E, Wasserman M. \& Espinal C. Separation and concentration of schizonts of Plasmodium falciparum by Percoll gradients. J Parasitol 1983; 30, 37-370.

8. Abele et al. Alterations in serum proteins and $19 \mathrm{~S}$ antibody production during the course of induced malarial infections in man. Am J Trop Med Hyg 1965; 14: 191-197.

9. Brown K, Berzins K, Jarra W, Schetters T. Immune responses to erythrocitic malaria. Clin Immunol Aller, 1986; (6), 1: 227-249.

10. Perrin L, Dayal R. Immunity to asexual erythrocytic stages of $P$. falciparum. Role of defined antibodies in the humoral response. Immunol Rev 1982; 61: 245-269.

11. Salaman $\mathrm{MH}$, Wedderburn $\mathrm{N}$. The immunodepresive effects of murine Plasmodium and its interactions with murine oncogenic viruses. J Gen Microbiol 1969; 59: 383.

12. Wyler DJ. Cellular aspects of immunoregulation in malaria. Bull. WHO. 1979; 57 (suppl. 1) 239.

13. Druilhe $\mathrm{P}, \mathrm{Khusmith} \mathrm{S}$. Epidemiological correlation between levels of antibodies promoting merozoite phagocytosis of $P$. falciparum and malaria immune status. Infect Immun 1987; 55, 4 888-891.

14. Celada A, et al. Phagocytosis of Plasmodium falciparum parasitized erythrocytes by human polymorphonuclear leukocytes. J Parasitol. 1983; 69, 1: 49-53. 